\title{
CAPACIDADES NECESSÁRIAS À PRÁTICA DOCENTE EM CIÊNCIAS CONTÁBEIS: SOCIALIZANDO RESULTADOS
}

Necessary skills to teaching practice in accounting: Socializing results

Habilidades necesarias para la práctica de la enseñanza en contabilidad: Socializar resultados

\section{Leonardo dos Santos Bandeira ${ }^{1}$}

${ }^{1}$ Curso de Ciências Contábeis, Centro Universitário ITPAC, Araguaína - TO, Brasil.

*Correspondência: Instituto Tocantinense Presidente Antônio Carlos, Faculdade de Ciências Humanas, Econômicas e da Saúde de Araguaína. Avenida Filadélfia - Setor Oeste. 77816540 - Araguaína, TO. E-mail: leonardobandeira@itpac.br

\section{Artigo recebido em 06/01/2017 aprovado em 04/05/2017 publicado em 06/06/2017.}

\section{RESUMO}

O presente trabalho propõe analisar, sob a ótica das teorias da educação, a respeito dos saberes e competências necessárias ao professor de Ciências Contábeis. As recentes pesquisas sobre essa temática tem demonstrado um perfil docente carente de capacidades profissionais específicas exigidas ao professor-contador. O estudo se desenvolve sob uma abordagem qualitativa do problema, pautado na pesquisa bibliográfica e em objetivos descritivo-exploratórios. Pretendeu-se enumerar, por meio da socialização de resultados de pesquisas anteriores, quais as capacidades são necessárias aos professores que ensinam tal ciência para que os discentes alcancem as competências que exigem o novo mercado. A pesquisa bibliográfica foi realizada no período de 2016/2 a 2017/1 no âmbito do banco de dados do indexador Google Acadêmico, por meio de palavras chaves inerentes ao problema da pesquisa. Nota-se que a busca por uma formação contínua refletida na construção permanente dos saberes docentes específicos e na transformação formativa e metodológica, com vistas à qualificação pedagógica, didática e contábil, precisa ser uma constante na carreira do professor-contador, sobretudo formação de natureza stricto sensu, para que atenda com eficácia ao processo de ensino e aprendizagem.

Palavras-chave: Saberes docentes. Ensino de contabilidade. Capacidades docentes.

\section{ABSTRACT}

The present study proposes to examine, from the perspective of theories of education, respect for knowledge and skills needed to Professor of Accounting. The recent research on this subject has shown a profile specific professional capabilities lacking teacher required professor-counter. The study develops under a qualitative approach to the problem, based on literature search and descriptive-exploratory goals. It was intended to enumerate through the socialization of results from previous searches, what capabilities are needed by professors who teach about science so that students achieve the skills that require the new market. The bibliographic research was carried out in the period from 2016/2 a 2017/1 within the Google Scholar indexer database, through key words inherent to the reserach problem. Note that the search for a continuous training reflected in permanent construction of knowledge professors and training and methodological transformation, with a view to pedagogical, didactical and accounting qualification, needs to be a constant in the career of professor-counter, especially formation of nature strict sensu, to answer efficiently to the teaching and learning process.

Keywords: Knowing professors. Accounting education. Teaching capabilities.

\section{RESUMEN}

El presente estudio se propone examinar, desde la perspectiva de las teorías de la educación, el respeto a los conocimientos y habilidades necesarias al profesor de contabilidad. La investigación reciente sobre este tema ha mostrado un perfil de capacidades profesionales específicas carecer de profesor requerida profesor-contador. El estudio se desarrolla bajo un enfoque cualitativo del problema, basado en la búsqueda de literatura y objetivos 
descriptivo exploratorio. Se pretende enumerar a través de la socialización de los resultados de búsquedas anteriores, qué capacidades son necesarias por los profesores que enseñan sobre la ciencia para que los estudiantes logren las habilidades que requieren el nuevo mercado. La investigación bibliográfica fue realizada em el período de 2016/2 a 2017/1 en la base de datos del Google Académico, por médio de descriptores inherentes al problem de la investigación. Tenga en cuenta que la búsqueda de una formación continua reflejada en la construcción permanente de los profesores de conocimiento y transformación metodológica y capacitación, con miras a la cualificación pedagógica, didáctica y contable, debe ser una constante en la carrera de contador de profesor, sobre todo formación de naturaleza stricto sensu, para responder eficientemente a la enseñanza y aprendizaje.

Descriptores: Conocimiento de maestros. Educación de contabilidad. Capacidades de enseñanza.

\section{INTRODUÇÃO}

Pesquisas sobre formação de professores têm crescido de forma expressiva nos últimos anos, sobretudo na década de 90, onde estudos voltados para os saberes e práticas docentes reflexivas começaram a se expandir. Renomados autores do campo da educação (SHULMAN, 1986, 1987; SCHÖN, 1987; CANDAU, 1997; GAUTHIER et. al., 1998; PERRENOUD, 2000; PIMENTA e ANASTASIOU, 2002; PIMENTA, 2012 TARDIF, 2014; SILVA et. al., 2015) têm produzido pesquisas nesta temática, preocupando-se principalmente com a profissionalização, a identidade e as capacidades docentes (conhecimentos, saberes e competências), formadas a partir da construção dos saberes e da prática pedagógica.

Segundo Borges (2011, p. 1), "pelo menos nos últimos 20 anos [...], a partir de concepções e orientações variadas, milhares de pesquisas sobre ensino, os docentes e seus saberes têm sido produzidas [...]”. Essa preocupação com a formação dos professores é reflexo da considerável expansão dos cursos de ensino superior nos últimos anos, inclusive de pós-graduação, e uma consequente necessidade de ampliação do corpo docente, melhoria da qualidade de ensino e eficácia do processo ensinoaprendizagem.

Essa preocupação dos pesquisadores em investigarem a identidade profissional, formada a partir das capacidades e experiências docentes, aplica-se de igual modo aos cursos de bacharelado em Ciências Contábeis, onde é comum encontrar professores que adentraram ao exercício da docência universitária apenas com os conhecimentos técnicos e específicos das disciplinas, uma vez que na graduação, notadamente a nível de bacharelado, o profissional não teve contato com disciplinas voltadas para uma perspectiva social e filosófica no campo da docência e, tampouco, para conhecimentos pedagógicos e didáticos.

Muitas instituições mantêm em seu currículo disciplinas de cunho filosófico, sociológico e psicológico, mas, por serem em sua maioria cursos de bacharelado, existe a inviabilidade de matrizes com perfil didático-pedagógico. É percebido que o egresso bacharel em Ciências Contábeis, ao desejar adentrar no campo docência universitária, dedica-se inicialmente a cursar pós-graduação lato sensu em docência ou metodologia do ensino superior ou outra que o qualifique para tanto.

O curso de Ciências Contábeis no Brasil, nos últimos anos, tem crescido de forma expressiva. No período de 2011 a 2015, pelo menos 170 novos cursos entraram em atividade no país, como evidenciado: 
Tabela 1. Número de cursos de Ciências Contábeis Presenciais e a Distância por Categoria Administrativa, Brasil de 2011-2015.

\begin{tabular}{cccc}
\hline Ano & Públicas & Privadas & Total \\
\hline 2011 & 170 & 934 & 1.104 \\
2012 & 192 & 972 & 1.164 \\
2013 & 194 & 1.013 & 1.207 \\
2014 & 193 & 1.063 & 1.256 \\
2015 & 178 & 1.096 & 1.274 \\
\hline
\end{tabular}

Fonte: Sinopses Estatísticas da Educação Superior Graduação (INEP, 2011-2015). Tabulação do autor.

Esse crescimento traz consigo questionamentos a respeito da qualidade do ensino, da qualificação dos bacharéis egressos e principalmente da capacitação e formação dos professores, visto que "uma educação eficaz e de qualidade sustenta-se, de certa forma, em seu corpo docente" (CORNACCHIONE, 2004, p. 7).

Com essa expansão acelerada, muitas Instituições de Ensino precisaram contratar docentes sem a devida capacitação pedagógica ou didática para tanto, detendo somente de conhecimentos específicos e técnicos da área contábil, se ausentando as capacidades de cunho docente (ANDERE e ARAÚJO, 2008).

Andere e Araújo (2008, p. 92) entendem que "estudar a educação e a qualidade do ensino contribui para a promoção de mudanças e para o progresso da sociedade, principalmente nesse momento de rápida expansão dos cursos de Ciências Contábeis no país [...]".

Desse feito, a pesquisa objetiva a investigação de quais os saberes e competências, que nomear-se-ão capacidades docentes, são necessárias à prática pedagógica dos docentes de Ciências Contábeis com base em pesquisas anteriores; contextualizar a temática das capacidades docentes balizando-se em estudos do campo da pedagogia/educação e compilar de forma não exaustiva as capacidades verificadas e socializadas nas pesquisas do que tratam os objetivos anteriores.
Comunelo et. al. (2012) afirmam que estudos sobre a formação de professores e pesquisadores em contabilidade importam no processo de desenvolvimento do ensino, pois instigam reflexões acerca da qualificação docente, o que se mostra relevante, especialmente diante das recentes mudanças que a ciência tem sofrido. Essa importância para o processo de desenvolvimento do ensino mantém consequência direta na formação dos alunos e na atuação profissional dos mesmos.

Pretende-se, além dos objetivos propostos, cooperar com pesquisas futuras a respeito da qualificação e capacidades dos docentes das Ciências Contábeis, proporcionando especificidades e destaques ao socializar e compilar resultados de pesquisas anteriores.

A presente pesquisa é de natureza básica e utiliza-se do método dedutivo-monográfico. Aborda o problema de forma qualitativa, tratando os objetivos de forma descritivo-exploratória e visa, por meio da pesquisa bibliográfica, solucionar a seguinte questão problema: diante das relevantes transformações das Ciências Contábeis, enquanto ciência social, quais as capacidades docentes são necessárias aos professores que ensinam tal ciência, com base na socialização de resultados de pesquisas anteriores, para que os discentes alcancem as competências que exigem o novo mercado?

O trabalho organiza-se em quatro seções, além desta introdução. A seção Materiais e Métodos apresenta os procedimentos e métodos científicos aplicados na busca pelos resultados apresentados. Posteriormente, apresenta-se uma contextualização a respeito das capacidades docentes necessárias à docência, baseada nos estudos da área da educação/pedagogia, seguida da discussão e socialização dos resultados sobre as capacidades necessárias ao professor que ensina contabilidade. 
Por fim, são tecidas as considerações finais da pesquisa e análise dos resultados.

\section{MATERIAIS E MÉTODOS}

O objetivo da pesquisa científica é buscar, selecionar, ordenar, elaborar e sistematizar uma massa de informações para transformá-la em conhecimento (PESCUMA e CASTILHO, 2005) e deve ser realizada subsidiada pelos métodos científicos, que são procedimentos técnicos que favorecem e norteiam o alcance dos objetivos estabelecidos.

A presente pesquisa é de natureza básica, não havendo uma aplicação prática imediata, mas sim geração de conhecimentos novos, conforme definido por Silva (2008). O tema foi abordado de forma qualitativa, aplicando-se o método dedutivomonográfico, não havendo utilização de dados estatísticos como centro do processo de análise do problema (SILVA, 2008) e pelo fato da mesma preocupar-se com aspectos que não podem ser quantificados.

Os objetivos foram trabalhados de forma descritivo-exploratória, levando em consideração a realização de análises, observação, classificação e descrição de dados e a devida obtenção de informações referente ao problema. Utilizou-se a pesquisa do tipo bibliográfica com a finalidade de atingir os objetivos apresentados.

A pesquisa bibliográfica, ou de fontes secundárias, é o tipo de pesquisa onde se realizam estudos e análises em referenciais teóricos e bibliografia já tomada pública em relação ao tema de estudo (LAKATOS e MARCONI, 2010, p. 166).

O objetivo central é socializar resultados de pesquisas concluídas com a temática dos saberes e competências necessárias à prática pedagógica de professores e de pesquisas específicas na área da docência em Ciências Contábeis.

Realizou-se uma coleta de bibliografias dos autores renomados da área de educação, para contextualizar a temática da pesquisa, e em seguida de pesquisas concluídas com a temática da docência na das Ciências Contábeis. A pesquisa bibliográfica foi realizada no período de 2016/2 a 2017/1 no âmbito do banco de dados do indexador Google Acadêmico, utilizando as palavras chaves: Saberes docentes; capacidades docentes; formação de professores em Ciências Contábeis; qualificação pedagógica docente; identidade e profissionalização docente. Após analisar todos os resultados, extraíramse as principais capacidades docentes apontadas pelos autores como necessárias à prática do professor de Ciências Contábeis, compilando-as em um quadro resumo para a análise de conteúdo. Os métodos posteriores constituíram-se da lapidação dos dados e informações coletadas, análise de conteúdo e emissão dos resultados obtidos.

\section{DISCUSSÃO E RESULTADOS}

\section{Capacidades Docentes: Contextualização}

A atuação dos docentes possui reflexos diretos na sociedade, pois a preparação de todos os profissionais que necessitam de formação especializada está sob sua égide pedagógica. Para muito além da base técnico-científica, o docente é responsável por possibilitar ainda a construção de uma formação prática, ética, social e humana (ALMEIDA e PIMENTA, 2011).

Os desafios a serem tomados frente às transformações sociais e que permeiam o campo de atuação docente e a participação da educação superior de capacitar e inserir o educando no mercado de trabalho com capacidades satisfatórias atribui ao 
professor uma obrigatoriedade de ressignificação de suas práticas e métodos (ROLIM et. al., 2014).

Para que o educando possa ser inserido no mercado com capacidades satisfatórias, capaz de atender às demandas profissionais que lhe são exigidas, o processo de ensino e aprendizagem precisa também ser satisfatório e eficaz. A ressignificação de práticas e métodos surge com a necessidade de uma construção de capacidades (saberes, conhecimentos, competências e métodos) necessárias à sua atuação docente (TARDIF, 2014; PUENTE, 2009).

Desde as décadas de 1980 e 1990 se discute a temática dos saberes e competências docentes e suas ressignificações. Os saberes docentes não são constituídos de um conhecimento ou técnica específica, mas por diferentes saberes, de diversas origens, incluindo o saber-fazer e o saber experiencial (SILVA et. al., 2015). Saberes e competências são, portanto, um "conjunto de capacidades mais ou menos sistematizadas necessárias para pôr em prática a profissão de professor [...]" (PUENTES et. al., 2009).

O saber-fazer está estreitamente ligado à didática e aos métodos pedagógicos de ensino; o saber experiencial compreende a experiência do ato docente e ainda a dinâmica do professor com a disciplina/conteúdo que ensina. Existem, portanto capacidades mínimas necessárias para que o fazer docente seja posto em prática, e tais capacidades se formam na construção da identidade docente, na trajetória pessoal dos sujeitos.

Para Tardif (2014), “[...] a questão do saber dos professores não pode ser separada das outras dimensões do ensino [...]", desconsiderando assim as realidades socais, organizacionais e humanas. As capacidades, como serão chamados os saberes e competências necessárias ao docente, não se constroem de forma linear, mas dinâmica, com base nas trajetórias de cada sujeito e profissionalidade específica (LACERDA, 2015).

"Os conhecimentos necessários à docência estão relacionados àquilo que os professores deveriam compreender sobre a docência a fim de favorecer o processo de ensino e aprendizagem eficiente" (PERAZO et. al., 2014).

$\mathrm{O}$ processo de ensino-aprendizagem, para tornar-se um feito eficiente, exige uma participação ativa de todos os sujeitos. O docente precisa deter de capacidades que permitam ao discente observar, analisar, selecionar e transformar a informação em novo conhecimento.

As capacidades docentes, entendidas como a pluralidade das competências, conhecimentos e saberes necessários ao professor, são construídas no processo formativo, na identidade pessoal do docente e na prática pedagógica. (PIMENTA, 2012; TARDIF, 2014).

Tardif (2014), ao referir-se ao saber plural docente, define quatro dimensões dos saberes docentes: os saberes de formação profissional (transmitidos pelas instituições formativas), saberes disciplinares (saberes dos diferentes campos do conhecimento compilados em disciplinas/currículo), saberes curriculares (métodos, conteúdos e formas de se aplicar os saberes disciplinares) e os saberes experienciais (resultantes do próprio exercício profissional, seja docente ou não).

Para Cardoso et. al.:

O saber profissional dos professores é, portanto, na interpretação de Tardif, uma amálgama de diferente saberes, provenientes de fontes diversas, que são construídos, relacionados e mobilizados pelos professores de acordo com as exigências de sua atividade profissional. Essa é a justificativa apresentada pelo autor para que se considerem inúteis as tentativas no sentindo de conceber uma classificação para os saberes docentes de acordo com critérios isoladamente da sua origem, seu uso ou ainda suas condições de apropriação e construção (CARDOSO et. al., 2012, p. 4). 
Tardif (2014) tipifica os saberes docentes norteado pela origem dos mesmos. O professor precisa construir durante seu processo formativo, os saberes profissionais que the proporcionarão uma capacitação base para então deter dos saberes disciplinares e curriculares. Os saberes de experiência são consequência da prática profissional (seja docente ou técnica).

Pimenta (2012), em Formação de Professores: Saberes da Docência e Identidade do Professor, analisa as práticas docentes como o caminho para repensar a questão dos saberes que constituem a docência. Em sua tese, compila três categorias de saberes necessários: os saberes experienciais (aqueles que os professores produzem no seu cotidiano docente e que são adquiridos ao longo da academia como discentes), os saberes do conhecimento (ato de trabalhar com as informações, classificando-as, analisando-as e contextualizando-as) e os saberes pedagógicos (conhecimentos didáticos e pedagógicos).

Pimenta e Anastasiou (2002) constituíram as tipologias de saberes e dividiram os saberes pedagógicos em: saberes pedagógicos propriamente ditos (pensar o ensino como prática educativa) e os saberes didáticos (articulação para ensinar).

Pimenta (2012) entende que o professor, ao chegar ao exercício da docência, já possui experiência do que é ser professor e a adquire a partir da vivência com seus professores referência enquanto discente. Os saberes do conhecimento se constituiriam da capacidade do professor em transpor, de forma didática, a informação em conhecimento escolar.

Candau (2012, p. 13), a respeito da didática, diz que "todo processo de formação de educadores especialistas e professores - inclui necessariamente componentes curriculares orientados para o tratamento sistemático do "que fazer" educativo [...]". A partir da prática pedagógica concreta e suas determinantes, a didática analisa os diferentes métodos procurando repensar as dimensões técnica, humana e política do processo de ensinoaprendizagem.

Mais conhecido internacionalmente que os trabalhos anteriores, Gauthier et. al. (1998) são responsáveis pela teoria da construção do reservatório de saberes. "É pertinente conceber o ensino como a mobilização de vários saberes que formam uma espécie de reservatório no qual o professor se abastece para responder às exigências específicas de sua situação concreta de ensino" (GAUTHIER et. al., 1998, p. 28).

Gauthier et. al. (1998), ao destacarem a pluralidade dos sabres, posicionam-se de modo a segregá-los em ofício sem saberes ou saberes sem ofício em direção a um ofício construído por saberes.

O ofício sem saberes abrange a ausência da sistematização de saberes propriamente docentes; os saberes sem ofício são os que não contribuem para a profissionalização docente; enquanto os ofícios feitos de saberes constituem os vários saberes mobilizados pelos professores em sua prática, a saber: saberes disciplinares, curriculares, das ciências da educação, da tradição pedagógica, da experiência e da ação pedagógica (SILVA et. al., 2015).

Cardoso, Del Pino e Dorneles (2012), ao confrontarem os estudos de Gauthier et. al. (1998), destacam:

O objetivo principal dos estudos desenvolvidos por Gauthier et. al. é argumentar no sentindo de que a profissionalização da docência está diretamente relacionada à legitimação e institucionalização dos saberes profissionais dos professores que, a partir desse processo, passariam a controlar a utilização e a reprodução desses saberes pelas instituições destinadas à formação de novos docentes (CARDOSO et. al., 2012, p. 10). 
Outra base teórica a respeito do tema é a construída por Shulman (1986; 1987). O autor propõe uma categoria de saberes docentes construídos sobre duas bases: Conhecimento para o Ensino e Processo Pedagógico. E essas categorias ou bases envolvem “[...] conhecimento curricular [domínio dos materiais e programas], conhecimento do conteúdo específico [da disciplina que leciona], conhecimento pedagógico geral [enquanto estratégia de organizar-se em sala de aula] e conhecimento pedagógico do conteúdo [disciplinar + pedagógico]" (SILVA et. al., 2015, p. 145).

A teoria de Shulman $(1986 ; 1987)$ surge na década de 80 , numa época em que a questão dos saberes docentes começava a tornar-se relevante. $\mathrm{O}$ programa do autor ficou conhecido como knowledge base, em livre tradução base de conhecimento, e define o conhecimento da matéria ensinada, o conhecimento pedagógico da matéria e o conhecimento curricular como a consolidação dessa corrente numa perspectiva da cognição e das ações docentes.

Pesquisas no campo da docência contábil (NOSSA, 1999; ANDERE e ARAÚJO, 2008; MIRANDA, 2011; MIRANDA et. al., 2012; FONTELES e OLIVEIRA, 2011; PERAZO et. al., 2014; ALMEIDA et. al., 2011; MALUSÁ et. al., 2015), têm mostrado grandes preocupações a respeito da formação profissional, concepções do processo ensino-aprendizagem, saberes necessários e da profissionalização docente aos professores de Ciências Contábeis e que serão socializadas nesta pesquisa.

Tais capacidades até então abordadas possibilitarão aos docentes uma prática profissional reflexiva e permitirão com que os mesmos alcancem “[...] a condição fundamental de educador para além de instrutor, treinador, comunicador, [...] líder teórico e prático de processos construtivos de conhecimento e da cidadania" (DEMO, 1994, p. 55 apud ANDERE e ARAÚJO, 2008, p. 95).

\section{Capacidades necessárias à prática do professor que ensina contabilidade: socialização de resultados}

Ensinar contabilidade é um ato de constante desafio em decorrência das mudanças que afetam a ciência. A adoção aos padrões internacionais e os avanços tecnológicos que mudam a cada dia o ensino da ciência fazem com que docentes com qualificação exclusivamente técnica, e sem capacidades didáticopedagógicas, não estejam aptos a contribuírem com a eficiência esperada do processo ensinoaprendizagem, não favorecendo ao discente alcançar as competências exigidas pelo novo mercado (MIRANDA, 2011; MIRANDA et. al., 2012).

O docente em Ciências Contábeis necessita tornar sua prática pedagógica num processo de autoaprendizagem. Segundo Tardif et. al. (1991, p. 219), "quanto mais um saber é desenvolvido, formalizado, sistematizado, como acontece com as ciências e os saberes contemporâneos, [...] mais se exige uma formalização e uma sistematização adequada".

Estudos como o de Miranda (2011) e Miranda et. al. (2012), focam na formação pedagógica dos docentes que atuam no ensino superior, sobretudo no curso de Ciências Contábeis. $\mathrm{O}$ autor afirma que os bacharéis têm acesso a conteúdo de natureza pedagógica somente quando optam por cursar disciplinas relacionas à metodologia do ensino superior em programas de pós-graduação, notadamente stricto sensu, ou quando buscam formação na área educacional.

$\mathrm{O}$ autor investigou as qualificações do professor e seus reflexos no desempenho discente nos cursos de Ciências Contábeis no Brasil e as discussões apontadas pelo autor sintetizam que há a 
necessidade de desenvolvimento de três qualificações docentes, no campo do ensino de Contabilidade: qualificação pedagógica, qualificação profissional e qualificação acadêmica.

Perazo et. al. (2014), com base nos estudos de Miranda (2011) e Miranda et. al. (2012), corroboram ao reiterar que essas competências são de suma importância enquanto capacidades necessárias aos docentes que ensina contabilidade e elucidam que:

'A qualificação acadêmica refere-se à preparação do docente para o exercício da pesquisa sobre os temas que leciona. A qualificação profissional indica a ligação do docente com a experiência adquirida através das práticas contábeis vigentes no campo profissional. E, os saberes experienciais, estão estritamente ligados ao domínio do conteúdo. São os saberes que nascem com a prática e por ela são validados (PERAZO et. al. 2014, p. 6).

Essa formação complexa proposta por Miranda (2011) é adquirida, sobretudo, por meio da experiência de mercado e com a formação contínua (capacitação, lato e stricto sensu). O que o autor propõe é que o docente esteja capacitado por meio da pesquisa, da experiência contábil e do saber de conteúdo.

O estudo de Nossa (1999) reflete de modo geral sobre as deficiências encontradas no ensino superior, sobretudo a importância dada pela sociedade e pelo governo. Diante dessa reflexão o autor procura focar no caso específico do ensino de contabilidade e objetiva solucionar o porquê da deficiência na formação docente dos professores em contabilidade e quais as propostas de melhoria de formação tendentes a solucionar tal situação. Nossa (1999, p. 7) destaca que "[...] uma das maiores deficiências na educação contábil no Brasil é a falta de treinamento para os professores dos cursos de Ciências Contábeis".

Além de tais deficiências, o autor, como causa do baixo desempenho dos professores sujeitos da pesquisa, detectou os seguintes motivos: I. expansão dos cursos, obrigando as instituições contratarem professores com pouca experiência acadêmica; II. falta de investimento por partes das instituições de ensino; III. maior atratividade do mercado profissional; e IV. reduzido número de cursos stricto sensu, pouca pesquisa e conhecimento cultural e humanístico (NOSSA, 1999).

$\mathrm{O}$ resultado obtido com a pesquisa foi a existência de um círculo vicioso no ensino e descaso com a educação diante da expansão extraordinária dos cursos nos últimos anos, segundo o estudo. Contribui afirmando que “[...] é indispensável a conscientização da necessidade de buscar novos conhecimentos, novas técnicas de ensino, enfim, de se comprometerem com a educação" (NOSSA, 1999, p. 17).

Mesmo sendo uma pesquisa realizada na década de 90, a mesma ainda se faz muito atual diante dos resultados, pois confrontando-a com o estudo realizado por Perazo et. al. (2014) observa-se que ainda existe a necessidade de formação continuada e atualização permanente dos docentes, ou seja, qualificação acadêmica e pedagógica.

Perazo et. al. (2014), inspirados nos estudos de Miranda (2011), realizaram um estudo de identificação do perfil dos docentes dos cursos de Ciências Contábeis de três Instituições de Ensino Superior (IES) públicas no Rio Grande do Sul, em termos de qualificação acadêmica, profissional e saberes experienciais. Por meio de uma abordagem quantitativa do problema, analisaram currículos na Plataforma Lattes de docentes e detectaram que a maioria possuía conhecimentos necessários à docência no que tange à qualificação acadêmica, porém um número reduzido não havia se qualificado profissionalmente, enquanto pelo menos a metade dos docentes possuía conhecimento prático. Contribuem e concluem de que ainda é necessário investir em 
qualificações acessórias, sobretudo nos âmbitos acadêmico e pedagógico:

É preciso investir em qualificações acessórias, nos âmbitos acadêmico, pedagógico e profissional para que o processo de ensino e aprendizagem seja constantemente melhorado, pois ensinar contabilidade requer conhecimentos e habilidades que extrapolam a formação do contador. Isso faz com que a prática docente seja um desafio diante da diversidade de conhecimentos que precisam ser renovados e práticas que requerem reflexos sobre o ato de pesquisar (PERAZO et. al., 2014, p. 14).

Os estudos de Almeida et. al. (2011) focam nas medidas adotadas pelas IES federais visando a qualificação e formação dos professores diante da adoção brasileira aos padrões internacionais de contabilidade. Apontam a qualificação dos docentes como a principal dificuldade em relação ao ensino das novas práticas e as deficiências em ações práticas visando o aperfeiçoamento docente nessa área, resumindo-se, principalmente, a oferta de palestras. Como mencionado, o processo de evolução das Ciências Contábeis provoca impacto direto no ensino da mesma, tornando-se imprescindível a necessidade de formação e qualificação de professores, como apontam os autores:

O docente deve ser um agente de integração da universidade com a comunidade e para isso deve estar bem preparado e atualizado com a realidade da disciplina lecionada. A aprendizagem contínua é pressuposto da profissão contábil e na área acadêmica a atualização é fundamental (ALMEIDA et. al., 2011, p. 7).

O conhecimento contábil revela-se endógeno e reproduzido sem questionamentos, as estratégias de ensino são centralizadas pela avaliação somatória e classificatória. Ou seja, esse método intrínseco de transferir conhecimento é uma prática errônea, pois o aluno precisa estar subsidiado de mecanismos que o favoreça no processo de construção pessoal do conhecimento. (LAFFIN, 2005)
Demo (2001) salienta que a avaliação tem como objetivo favorecer o aluno num processo em que ele possa argumentar e contra argumentar, e, assim, encontrar solução para os desafios apresentados em forma de conteúdo por diferentes meios.

Com a aplicação dos métodos avaliativos classificatórios não há favorecimento para o avanço do desenvolvimento do aluno (LUCKESI, 2000). Uma avaliação coerente com uma educação de qualidade tem função diagnóstica e busca sempre novos rumos para o aprendizado.

Andere e Araújo (2008) pesquisaram a formação de professores analisando as percepções de coordenadores e professores de programas de pósgraduação stricto sensu, dada a importância que tais programas têm sob as formações prática, técnicocientífica, pedagógica e sócio-política dos docentes.

A relevância do estudo concentra-se na necessidade do professor de ensino superior em Contabilidade possuir uma formação completa, englobando os conhecimentos experienciais e de mercado (prática); os saberes teóricos específicos e em pesquisas acadêmicas (teórico-científico); os conhecimentos didáticos e saberes docentes (pedagógica) e conhecimentos sociais, econômicos e políticos que envolvam a realidade da própria profissão (sócio-político).

Analisando os programas de pós-graduação stricto sensu, os resultados obtidos já parecem serem contrários, onde a preocupação já não está voltada para o ensino demasiado teórico e técnico, onde os autores detectaram que o professor de ensino superior em contabilidade, dotado do título defendido, possui formação voltada apenas para a pesquisa científica, sem conhecimentos pedagógicos que o tornam capazes de aplicarem os conhecimentos teóricos. "Para que o professor de Contabilidade tenha uma formação completa, é necessário que os programas se 
preocupem mais com a formação prática, desenvolvendo a capacidade da aplicação da teoria na prática” (ANDERE e ARAÚJO, 2008, p. 101).

Malusá et. al. (2015) analisaram concepções da pedagogia universitária, formação de professores e saberes docentes presentes nas práticas e documentos de regulação dos cursos de Ciências Contábeis do triângulo mineiro e destacam que nos Projetos Político-Pedagógicos dos Cursos de Graduação (PPC) “[...] as reflexões acerca dos problemas sociais mais amplos não têm espaço, predomina a transmissão dos conhecimentos contábeis com ênfase no tecnicismo em face da inexistência de disciplinas que promovam essas reflexões" (MALUSÁ et. al., 2015, p. 313). Ou seja, a ênfase no tecnicismo e na abordagem conteudista ainda são práticas errôneas no ensino de contabilidade no país, onde a busca pela formação de profissionais reflexivos ainda é deficiente.

Torna-se evidente, desse feito, a necessidade de uma formação docente e pedagógica mais consciente e contínua. Os saberes docentes experienciais em Ciências Contábeis são os mais coerentes com a formação inicial. "É por meio de uma a formação inicial e contínua para a docência que tornará possível valer-se da própria experiência no magistério para refletir sobre a prática pedagógica vivenciada" (MALUSÁ et. al., 2015, p. 315).

Com os resultados até aqui socializados é possível observar que o desenvolvimento dos saberes docentes oriundos do processo de formação e da prática reflexiva do professor de Ciências Contábeis, frente às exigências atuais, fortalece a bagagem por ele já adquirida durante sua trajetória educativa (ROLIM et. al., 2014). Perrenoud (2000, p. 15) compreende esses saberes e competências como a "capacidade de mobilizar diversos recursos cognitivos para enfrentar um tipo de situação".

Por fim, salienta-se que a construção pedagógica e permanente de capacidades docentes transcende a dimensão técnica do ato de ensinar e da abordagem conteudista vivenciada nas salas de aula dos cursos bacharelado de Ciências Contábeis.

De modo a compilar todas as pesquisas socializadas, apresenta-se um quadro resumo que permite analisar as capacidades necessárias ao docente de Ciências Contábeis extraídas dos resultados auferidos pelos pesquisadores em discussão. Inserem-se também as capacidades apontadas como necessárias pelos pesquisadores do campo da educação e da pedagogia. O Quadro 1, em nenhuma hipótese, esgota ou finda os saberes e competências docentes necessários aos sujeitos das pesquisas, pois, como evidenciado, tais capacidades precisam estar em constante ressignificação e reconstrução com vista a adequarem-se ao cenário da ciência, ao mercado profissional e ao perfil dos sujeitos do processo de ensino e aprendizagem. 
Quadro 1. Resumo dos Resultados Socializados

\begin{tabular}{|c|c|c|}
\hline \multicolumn{3}{|c|}{ Capacidades docentes necessárias gerais } \\
\hline $\begin{array}{l}\text { Tardif } \\
(2014)\end{array}$ & $\begin{array}{l}> \\
> \\
>\end{array}$ & $\begin{array}{c}\text { Saberes de formação profissional; } \\
\text { Saberes disciplinares; } \\
\text { Saberes curriculares; } \\
\text { Saberes experienciais. }\end{array}$ \\
\hline $\begin{array}{l}\text { Pimenta } \\
(2012) ; \\
\text { Pimenta e } \\
\text { Anastasiou } \\
\quad(2002) \\
\end{array}$ & $>_{>}^{>}$ & $\begin{array}{l}\text { Saberes experienciais; } \\
\text { Saberes do conhecimento; } \\
\text { Saberes pedagógicos; } \\
\text { Saberes didáticos. }\end{array}$ \\
\hline $\begin{array}{l}\text { Gauthier et. al. } \\
\quad(1998)\end{array}$ & $\begin{array}{l}> \\
>> \\
>>\end{array}$ & $\begin{array}{c}\text { Saberes disciplinares; } \\
\text { Saberes curriculares; } \\
\text { Saberes das ciências da educação; } \\
\text { Saberes da tradição pedagógica; } \\
\text { Saberes experienciais; } \\
\text { Saberes da ação pedagógica. }\end{array}$ \\
\hline $\begin{array}{c}\text { Shulman } \\
(1986 ; 1987)\end{array}$ & $>^{>}$ & $\begin{array}{l}\text { Conhecimento curricular; } \\
\text { Conhecimento do conteúdo; } \\
\text { Conhecimento pedagógico; } \\
\text { Conhecimento pedagógico do } \\
\text { conteúdo. }\end{array}$ \\
\hline \multicolumn{3}{|c|}{ Capacidades docentes necessárias ao professor-contador } \\
\hline $\begin{array}{l}\text { Miranda } \\
\text { (2011) }\end{array}$ & $\begin{array}{l}> \\
>\end{array}$ & $\begin{array}{l}\text { Qualificação pedagógica; } \\
\text { Qualificação profissional; } \\
\text { Qualificação acadêmica. }\end{array}$ \\
\hline $\begin{array}{l}\text { Nossa } \\
(1999)\end{array}$ & $>$ & $\begin{array}{l}\text { Busca de novos conhecimentos e } \\
\text { técnicas de ensino; } \\
\text { Comprometimento com a } \\
\text { educação; } \\
\text { Formação stricto sensu. }\end{array}$ \\
\hline $\begin{array}{l}\text { Perazo et. al. } \\
\quad \text { (2014) }\end{array}$ & $\begin{array}{l}> \\
\text { (sobre } \\
\end{array}$ & $\begin{array}{l}\text { Formação continuada e } \\
\text { atualização permanente; } \\
\text { Qualificações acessórias } \\
\text { tudo pedagógica e acadêmica). }\end{array}$ \\
\hline $\begin{array}{l}\text { Almeida et. al. } \\
\text { (2011) }\end{array}$ & $\begin{array}{l}> \\
> \\
>\end{array}$ & $\begin{array}{l}\text { Aprendizagem contínua na área } \\
\text { contábil; } \\
\text { Atualização contínua na área na } \\
\text { acadêmica; } \\
\text { Ações de pesquisa, ensino e } \\
\text { extensão; } \\
\text { Atualização em novas práticas } \\
\text { docentes. }\end{array}$ \\
\hline $\begin{array}{c}\text { Andere e Araújo } \\
\text { (2008) }\end{array}$ & $\begin{array}{c}> \\
\text { específ } \\
> \\
> \\
\text { econôm }\end{array}$ & $\begin{array}{l}\text { Conhecimentos experienciais } \\
\text { (prática de mercado); } \\
\text { Conhecimentos teóricos } \\
\text { icos e em pesquisas acadêmicas } \\
\text { (teórico-científico); } \\
\text { Conhecimentos docentes e } \\
\text { didáticos (pedagógicos); } \\
\text { Conhecimentos sociais, } \\
\text { icos e políticos (sócio-políticos); } \\
\text { Capacidade da aplicação da teoria } \\
\text { na prática. }\end{array}$ \\
\hline $\begin{array}{l}\text { Malusá et. al. } \\
\quad \text { (2015) }\end{array}$ & $>\mathrm{m}$ & $\begin{array}{l}\text { Formação docente e pedagógica } \\
\text { hais consciente e contínua; } \\
\text { Formação inicial e contínua; } \\
\text { Saberes experienciais. }\end{array}$ \\
\hline
\end{tabular}

Fonte: resultados extraídos das pesquisas socializadas. Tabulação do autor. 
Predominam nas pesquisas a exigência do saber experiencial e específico, sobretudo de mercado, e a formação contínua, tanto em prática didático-pedagógicas quanto no campo técnico e contábil. A ausência do conhecimento prático pode prejudicar a explanação e exemplificação de temas técnicos e problemas contábeis, como por exemplo, a perícia contábil, a auditoria etc.; os conhecimentos específicos precisam ser reciclados e aprimorados no desenvolvimento de pesquisas, em detrimento da docência; quanto aos saberes didático-pedagógicos, se o professor não os detém, tão pouco deterá de uma preparação sistematizada para o exercício da docência e das metodologias de ensino (ANDERE e ARAÚJO, 2008; MIRANDA, 2011; MALUSÁ et. al., 2015).

As pesquisas (NOSSA, 1999; ANDERE e ARAÚJO, 2008; MIRANDA, 2011; MALUSÁ et. $a l .$, 2015) revelam a ausência de uma inter-relação entre a teoria e a prática do conhecimento, predominando técnicas de conteúdos mecânicos com aplicação de exercícios práticos em salas de aula. A docência em contabilidade "[...] muitas vezes tem se restringido à transmissão dos conhecimentos contábeis com ênfase no tecnicismo associado aos conteúdos mecanicistas [...]" (LAFFIN, 2005, p. 17).

Esse método de avaliação e transmissão do conhecimento tem sido criticado no campo da docência contábil. Tem-se percebido uma teoria distante da prática, mecânica e técnica, limitado à fixação por meio de atividades em sala de aula. No trabalho de Almeida et. al. (2011) foi possível observar que o conhecimento contábil é reproduzido de forma endógena, ou seja, um conhecimento intrínseco em que o aluno não tem espaço para argumentar e é avaliado por um método classificatório e somatório.

Frente a esses resultados e aos desafios que são inerentes à profissão docente e contábil do professor de Ciências Contábeis, é preciso investir, sobretudo, em qualificações, tanto acadêmica quanto profissional, numa formação continuada, visando capacitação didático-pedagógica, "para que o processo de ensino e aprendizagem seja constantemente melhorado, pois ensinar contabilidade requer conhecimentos e habilidades que extrapolam a formação do contador" (PERAZO et. al., 2014, p. 13). Isso corrobora para que o ato docente se torne um desafio perante a heterogeneidade de conhecimentos que precisam ser reciclados e presentificados, e diante de métodos e práticas reflexivas sob o ato de ensinar.

\section{CONCLUSÃO}

Este estudo teve por propósito investigar quais os saberes e competências docentes são necessárias à prática pedagógica de professores em Ciências Contábeis, tendo como subsídio investigatório a socialização de resultados já obtidos por pesquisas anteriores.

Inicialmente buscou-se em referências bibliográficas do campo da pedagogia/educação estudos acerca da temática das capacidades docentes (conhecimento, saberes e competências) para verificar quais são enumeradas como necessárias ao exercício docente no que diz respeito ao ato pedagógico, à didática, aos métodos avaliativos e a identidade profissional do professor.

Os estudos de Shulman (1986; 1987), Gauthier et. al. (1998), Pimenta e Anastasiou (2002), Pimenta (2012) e Tardif (2014) apontam para uma perspectiva tênue no que diz respeito à necessidade dos professores deterem saberes e conhecimentos experienciais, disciplinares e do conteúdo que ensina, pedagógicos, didáticos e das ciências da educação para uma ação pedagógica eficiente e que corrobore 
para a eficácia de resultados do processo de ensino e aprendizagem.

Quando se verificou pesquisas que analisaram as capacidades docentes necessárias aos professores-contadores, presentes nos resultados socializados, foi possível notar um corpo docente carente de especificidades, de formação continuada, qualificação profissional, pedagógica e didática.

Os resultados socializados das pesquisas levantadas revelam que os conhecimentos teórico e prático precisam estar em constante renovação e reavaliação, não como uma reciclagem pedagógica, mas como uma construção permanente do saber docente e de transformação formativa e metodológica. Esse processo de reavaliação é onde o professor “[...] aprende, desaprende, reestrutura o aprendido, faz descobertas e, assim, vai aprimorando sua formação" (Candau, 1997, p. 57).

Não somente a ciência contábil tem passado por consideráveis processos de transformação e evolução, portanto, mais do que nunca, é necessário que o professor se mantenha atualizado e em constante reconstrução, não somente com relação aos fatos e acontecimentos de transformação e evolução da sociedade, mas, impreterivelmente, em relação aos conhecimentos didáticos e pedagógicos, aos saberes docentes em evolução e às novas tendências e métodos educacionais.

A pesquisa enfrentou como limitações a ausência da determinação de um arcabouço teórico unânime a respeito das capacidades necessárias à prática docente, bem como de uma identidade profissional que corrobore nessa dimensão. Sugere-se para futuras pesquisas a investigação junto a professores que ensinam contabilidade se há em seus perfis docentes a presença das capacidades docentes apontadas como necessárias nos resultados aqui socializados, como medida de confirmá-las ou não.
Todos os autores declararam não haver qualquer potencial conflito de interesses referente a este artigo.

\section{REFERÊNCIAS}

ALMEIDA, S. R. et. al. Medidas adotadas pelas IFES brasileiras visando a qualificação docente e a adequação de conteúdos com a convergência internacional da contabilidade. In: CONGRESSO USP DE INICIAÇÃO CIENTÍFICA EM CONTABILIDADE, 8, 2011, São Paulo. Anais. São Paulo: USP, 2011.

ALMEIDA, M. I; PIMENTA, S. G. Docência universitária: passos de um percurso formativo. In: ALMEIDA, M. I; PIMENTA, S. G. (Orgs.). Pedagogia Universitária: caminhos para a formação de professores. São Paulo: Cortez, 2011, p. 7-16.

ANDERE, M. A; ARAÚJO, A. M. P. Aspectos da formação do professor de Ensino Superior de Ciências Contábeis: Uma análise dos Programas de Pós-Graduação. Revista Contabilidade e Finanças, USP, São Paulo v. 19, n. 48, p. 91-102, set./dez. 2008.

BORGES, C. Saberes Docentes: diferentes tipologias e classificações de um campo de pesquisa. Educação \& Sociedade, ano XXII, n. 74, 2011.

CARDOSO, A. A . et. al. Os saberes profissionais dos professores na perspectiva de Tardif e Gauthier: contribuições para o campo de pesquisa sobre os saberes docentes no Brasil. In: ANPED SUL SEMINÁRIO DE PESQUISA EM EDUCAÇÃO DA REGIÃO SUL, 9, 2012, Rio Grande do Sul. Anais. Rio Grande do Sul: ANPEd, 2012.

CANDAU, V. M. Formação continuada de professores: tendências atuais. In: CANDAU, V. M. (Org.). Magistério: construção cotidiana. Petrópolis: Vozes, 1997, p. 51-68.

A didática em questão. 33 ed. Rio de Janeiro: Vozes, 2012.

COMUNELO, A. L et. al. Programas de pósgraduação stricto sensu em contabilidade: sua contribuição na formação de professores e pesquisadores. Enfoque: Reflexão Contábil, v. 3, p. 07-26, 2012.

CORNACHIONE, JR. E. B. Tecnologia da educação e cursos de ciências contábeis: modelos colaborativos virtuais. 2004. Tese (Livre - docência). Faculdade 
de Economia, Administração e Contabilidade, Universidade de São Paulo, São Paulo, 2004.

DEMO, P. Saber pensar. 2. ed. São Paulo: Cortez, 2001.

GAUTHIER, C. et. al. Por uma teoria da pedagogia: pesquisas contemporâneas sobre o saber docente. 2. ed. Ijuí: Editora Unijuí, 1998.

INEP - INSTITUTO NACIONAL DE ESTUDOS E PESQUISAS EDUCACIONAIS ANÍSIO TEIXEIRA. Sinopses Estatísticas da Educação Superior - Graduação. Disponível em $<$ http://portal.inep.gov.br/web/guest/sinopsesestatisticas-da-educacao-superior >. Acesso em: 29 maio 2017.

LACERDA, C. R. Saberes necessários à prática docente no Ensino Superior: Olhares dos professores dos cursos de bacharelado. Revista Docência no Ensino Superior, v. 5, n. 2, p. 79-100, 2015.

LAFFIN, M. De contador a professor: a trajetória da docência no ensino superior de Contabilidade. Florianópolis: Imprensa Universitária, 2005.

LAKATOS, E. M.; MARCONI, M. A. Fundamentos de metodologia científica. 7. ed. São Paulo: Atlas, 2010.

LUCKESI, C. C. Avaliação da Aprendizagem Escolar. 10. ed. São Paulo: Cortez, 2000.

MALUSÁ, S. et. al. Ensino superior: concepções de pedagogia universitária no curso de Ciências Contábeis. Revista Educação e Cultural Contemporânea, Universidade Estácio de Sá, v. 12, n. 27, p. 289-319, 2015.

MIRANDA, G. J. Relações entre as qualificações do professor e o desempenho discente nos cursos de graduação em contabilidade no Brasil. 2011. Tese (Doutorado em Economia). Faculdade de Economia, Administração e Contabilidade. Universidade de São Paulo, São Paulo, 2011.

MIRANDA, G. J. et. al. Os saberes dos professoresreferência no ensino de contabilidade. Revista Contabilidade \& Finanças, v. 23, n. 59, p. 142-153, 2012.

NOSSA, V. Formação do corpo docente dos cursos de graduação em contabilidade no Brasil: uma análise crítica. Caderno de estudos da FIPECAFI, São Paulo, n. 21, maio/ago. 1999.

PERAZO, A. N. C. et. al. Perfil do docente de Ciências Contábeis: Perspectiva de sua qualificação acadêmica, pedagógica e profissional. In: CONGRESSO BRASILEIRO DE CUSTOS, 21, 2014 Natal. Anais. Natal: ABC, 2014.

PERRENOUD, P. 10 novas competências para ensinar. Porto Alegre: ArtMed, 2000.

PESCUMA, D.; CASTILHO, A. P. F de. Projeto de pesquisa: o que é? Como fazer? Um guia para sua elaboração. São Paulo: Olho d'Água, 2005.

PIMENTA, S. G. Formação de professores: identidades e saberes da docência. In: Pimenta, S. G. (Org.). Saberes pedagógicos e atividades de docência. São Paulo: Cortez, 2012.

PIMENTA, S. G.; ANASTASIOU, L. G. C. Docência no ensino superior. São Paulo: Cortez, 2002. (Coleção Docência em Formação, v. 1).

PUENTES, R. V. et. al. Profissionalização dos professores: conhecimentos, saberes e competências necessários à docência. Educar em Revista, n. 34, p. 169-184, 2009.

ROLIM, C. L. A. et. al. Docência no Ensino Superior: Formação continuada, saberes e práticas. In: SEMINÁRIO INTERNACIONAL DE EDUCAÇÃO SUPERIOR, 1, 2014, Sorocaba. Anais. Sorocaba: UNISO, 2014.

SCHÖN, D. A. Educating the reflective practitioner: toward a new designer for teaching and learning in the professions. San Francisco: Jossey Bass Publ, 1987.

SHULMAN, L. S. Those who Understand: Knowledge Growth in Teaching. Educational Researcher, v. 15, n. 2, p. 4-14, 1986.

Knowledge and Teaching: Foundations of the New Reform. Educational Review, v. 57, n. 1, p. 1-22, 1987.

SILVA, A. C. R. da. Metodologia da pesquisa aplicada à contabilidade: orientações de estudos, projetos, artigos, relatórios, monografias, dissertações, teses. São Paulo: Atlas, 2008.

SILVA, G. L. F et. al. Análise dos saberes docentes relativos ao trabalho docente com auxílio do software Atlas-TI. In: TOZETTO, S. S. Professor em formação: saberes, práticas e desafios. Curitiba: Inter Saberes, 2015. Cap. 5, p. 138-167.

TARDIF, M. et. al. Os Professores Face ao Saber: esboço de uma problemática do saber docente. 
Teoria \& Educação, n. 4, Porto Alegre, 1991, p. 215-253.
Saberes docentes e formação profissional.

$17 . \quad$ ed. Petrópolis: Vozes, 2014. 